\title{
Vibrations analysis of combine harvester seat in time and frequency domain
}

\author{
A. Jahanbakhshi1 ${ }^{1}$ B. Ghamari1 and K. Heidarbeigi'* \\ 1 Department of Mechanical Engineering of Biosystems, Ilam University, Ilam, Iran. Phone: +98-843222701
}

\begin{abstract}
Agricultural machineries as one of the main inputs in producing agricultural materials are associated with some problems on occupational health such as vibrations. At the lowest level, vibrations cause different diseases such as those affecting blood vessels, nerves, muscles, etc. The aim of this study was to determine and investigate the seat vibrations in John Deere 1055I combine harvester at different conditions. The experiments were carried out based on ISO 2631 and the Iranian standard number 14133. The tests were done at different engine revolutions and gear ratios with three replications. The collected data were analyzed considering factorial experiments based on completely randomized design. The results of variance analysis related to the effect of the main factors on combine seat vibrations showed a significant difference at the probability level of $1 \%$. Effect of engine revolutions on vibration of the combine seat was higher than that of shifting gears. By calculating the allowable exposure time, there was concluded that for the first and second gears at the engine revolution of $1800 \mathrm{rpm}$ and the first gear at the revolution of $2500 \mathrm{rpm}$, operators can easily drive the combine harvester for eight hours every day without any problems. The results of this study can be used to optimize the components affecting the vibration of the combine seat.
\end{abstract}

\author{
ARTICLE HISTORY \\ Revised: $3^{\text {rd }}$ Oct 2019 \\ Accepted: $11^{\text {th }}$ Nov 2019
}

\section{KEYWORDS}

Combine harvester;

seat;

vibration;

exposure time duration;

ergonomics.

\section{INTRODUCTION}

In internal combustion engines, power is produced by controlled combustions which create high-energy impacts in the engine. Each impact of combustion strikes the cylinder block similar to a hammer and produces vibrations in the engine. Demand for high forward speeds in agricultural operations increases the vibration and sound pressure levels and thus reduces driver performance [1-5]. These vibrations during farm operations cause drivers comfort and health risk [6]. Vibrations also cause musculoskeletal disorders and spinal injury with more prevalence in some parts of the body such as the shoulders, the neck and the waist [7]. In addition, exposure of driver's whole body to vibrations for long times might has destructive effects on physiological and psychological systems and also cause blurred vision, loss of balance or decrease in caution level [8,9]. De Temmerman et al. [10] found that land profile, long period of operation with a machine, agricultural machines' operation speed and the driver's positioning on the seat are the main factors that might cause harm to drivers.

Marsili et al. [11] determined vibration of a tractor seat equipped with a suspension system and a shock absorber. The results of their study showed that seat suspension system reduces vibration by $15-36 \%$ in various operating conditions. Hostens \& Ramon [12] conducted vibration experiments in the combine's cabin and on the seat and demonstrated that combine's cabin vibration on asphalt roads at the speed of $20 \mathrm{~km} / \mathrm{h}$ was lower than that on a farm road even at speeds lower than $20 \mathrm{~km} / \mathrm{h}$. It was also observed that a seat with air suspension system better than mechanical suspension system can reduce frequencies above $4 \mathrm{~Hz}$ and prepares more comfortable driver positions. Ahmadian et al. [13] studied the vibrations of the seat and handles in two-wheeled tractors during transportation time. They reported that vibration was increased at all gear levels by increasing engine revolution and vibration amplitude in vertical direction was higher than that of other directions. Pel et al. [14] conducted experiments on three drivers with weight of 62,81 and $100 \mathrm{~kg}$ in two stages with the frequencies of $25-50 \mathrm{~Hz}$ and $5-40 \mathrm{~Hz}$. The results indicated that horizontal vibration was reduced whereas vertical vibration was increased by decreasing driver's weight.

In Iran 14842 grain combine harvesters were used in 2013 [15]. According to this statistics, it can be concluded that annually at least 14842 combine operators are exposed to vibrations. Therefore, more attention must be paid to these operators' comfort and health situations and it seems necessary to determine how many hours the drivers can operate the combine at different gears and engine revolutions. In addition, the main sources of vibration can be identified in the combine and solutions can be recommended to improve or repair the vibration sources. By conducting research studies on seat vibration in John Deere 1055I combine and finding an appropriate solution to prevent harms to the users, a step can be taken forward to ensure operators' health and safety and increase that they can use this type of combine. The comprehensive review of studies carried out in this regard shows that unfortunately no efforts have been made to take the topic of combine users' health into consideration. 


\section{MATERIALS AND METHODS}

The different steps conducted in the present research have been shown in Figure 1. In this study, the tests were conducted on a John Deere 1055I Combine Harvester (Production year 2015, Iran Combine Manufacturing Company) with specifications presented in Table 1.

Table 1. Technical specifications of JD 1055I Combine harvester.

\begin{tabular}{ccccc}
\hline Engine type & $\begin{array}{c}\text { Number of } \\
\text { cylinders }\end{array}$ & $\begin{array}{c}\text { Cutting width } \\
(\mathrm{m})\end{array}$ & $\begin{array}{c}\text { Grain tank capacity } \\
(\text { lit })\end{array}$ & $\begin{array}{c}\text { Power } \\
\text { (hp) }\end{array}$ \\
\hline Diesel & 6 & 4.25 & $2710-3500$ & 119 \\
\hline
\end{tabular}

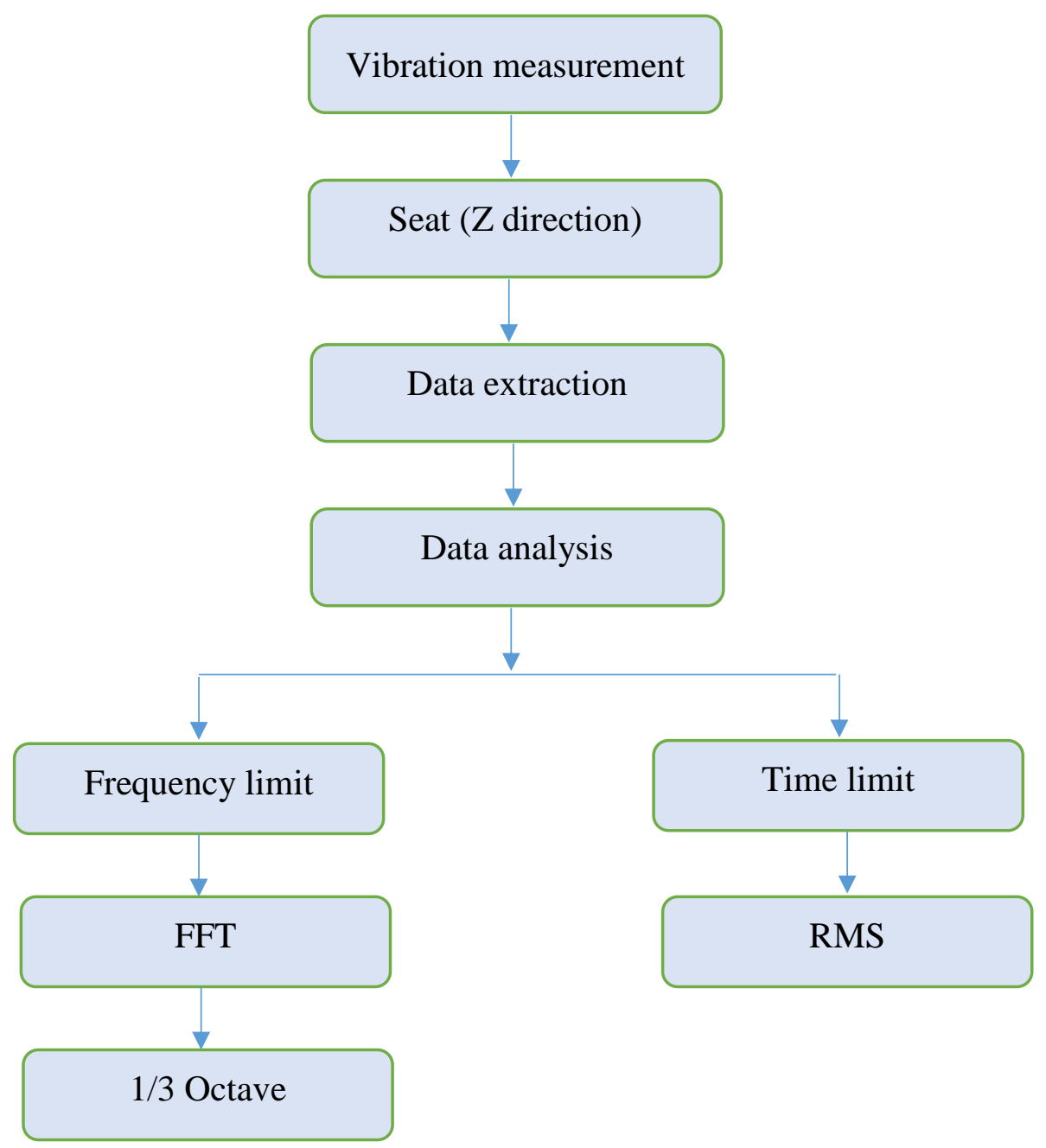

Figure 1. Different steps of vibration analysis in the present research.

The investigated factors in this study were engine revolution (at two levels of $1800 \mathrm{rpm}$ and $2500 \mathrm{rpm}$ ) and gear ratio (at 1,2 and 3 heavy gears) with three repetitions. The tests were conducted considering factorial experiment based on completely randomized design. A farm with orderly and regular topography was selected to operate the combine. Since agricultural machines' drivers are more sensitive to vertical vibrations, the combine vibrations transmitted through the seat to the driver were measured along perpendicular direction ( $\mathrm{Z}$ direction) $[16,17]$. Since driver weight effects on the results of vibration tests, the combine was operated by only one driver with weight of $78 \mathrm{~kg}$. In according to Iranian National Standard (no: 14133) a distance of $100 \mathrm{~m}$ was considered to measure and record combine seat vibration signals [18]. To measure vibrations, the Lurton-VB 8203 (Taiwan) vibration meter was used with the vibration acceleration range of $0.5-199 \mathrm{~m} / \mathrm{s}^{2}$, precision of $0.1 \mathrm{~m} / \mathrm{s}^{2}$ and frequency range of $10-1000 \mathrm{~Hz}$. The vibration meter was unidirectional and its sensor magnetically provides the possibility of fast and stable connection with a metal surface object. The sensor must not be under pressure and it would get damaged if the driver sits on it. Therefore to prevent damage and to obtain accurate results, a hole was made in combine seat with a diameter bigger than that of the vibration meter. A metal plate was built with area equal to seat area and constant thickness without any changing when the driver sat on it (Figure 2). 

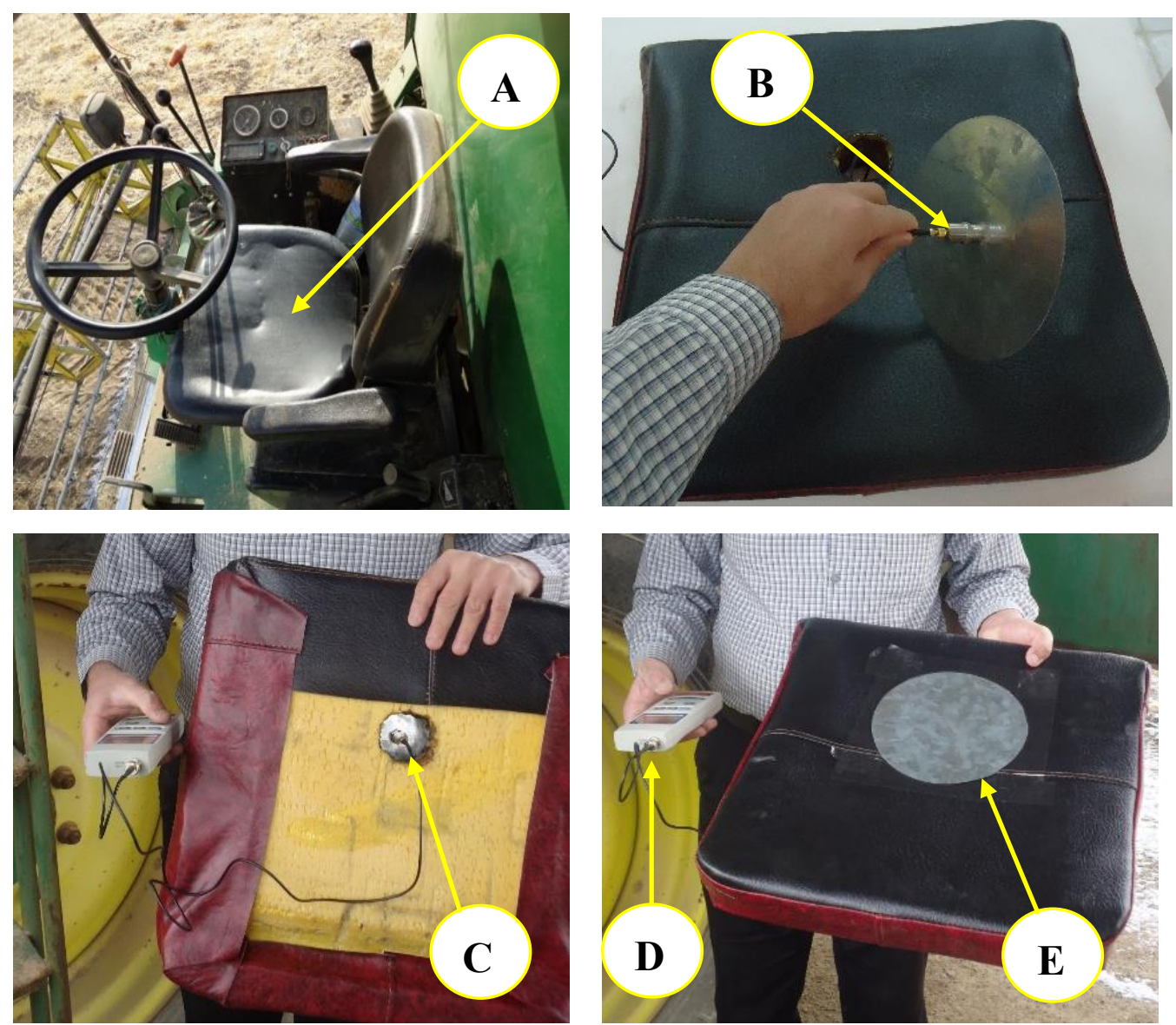

Figure 2. The combine harvester' seat and connecting vibration measurement equipment: A) Driver's seat, B) Vibration sensor, C) Location of vibration sensor to driver's seat, D) Vibration meter, and E) Vibration sensor holder plate.

The plate was stuck to the seat with strong glue and then tests were carried out to acquire seat vibration signals [18, 19]. Vibrations were transmitted from the sensor to the data logger and then transferred to and saved in a portable computer using an RS232 cable. Root mean square (RMS) of vibration was calculated in the time domain using Eq. 1 for continuous and integrated function.

$$
\mathrm{a}_{\mathrm{RMS}}=\left[\frac{1}{\mathrm{~T}} \int_{0}^{\mathrm{T}} \mathrm{a}_{(\mathrm{t})}^{2} \mathrm{dt}\right]^{1 / 2}
$$

where $a_{R M S}$ is root mean square of acceleration $\left(\mathrm{m} / \mathrm{s}^{2}\right), \mathrm{a}_{(\mathrm{t})}$ is acceleration $\left(\mathrm{m} / \mathrm{s}^{2}\right)$ and $\mathrm{T}$ is time of measuring (s). Microsoft Excel 2013 and SAS 9.1 were used for statistical analysis of obtained data based on completely randomized design to assess significance effects of the main factors and interactions. The Duncan's multivariate test was used to compare the effect of the factor levels on root mean square of vibration in the time domain [2, 3, 20]. Then collected data were transformed to frequency domain by Fast Fourier Transform (FFT) algorithm and the 1/3 octave band was extracted by MATLAB 2010a (The Mathworks Inc., Natick, MA, USA) and then the allowable exposure time was estimated for different operation conditions.

\section{RESULT AND DISSCUSSION}

\section{Variance Analysis}

The results of variance analysis for the main parameters and their interactions affecting on combine seat vibration in time domain have been shown in Table 2. As can be seen in this table, the effect of the main variables which measured such as engine revolutions (rpm) and gear ratio on combine seat vibration were significant at $1 \%$ probability level. This indicates that for both factors, at least one studied level has significant effect on the seat vibration. There was also observed that the interaction between engine revolution and gear ratio was not significant. 
Table 2. Variance analysis of factors affecting on combine seat vibration in time domain.

\begin{tabular}{lllll}
\hline Factor & DF & Sum of squares & Mean squares & F \\
\hline Engine revolution & 1 & 1.095 & 1.095 & $409.85^{* *}$ \\
Gear ratio & 2 & 2.719 & 1.359 & $508.84^{* *}$ \\
Engine revolution $\times$ Gear ratio & 2 & 0.0014 & 0.0007 & $0.27^{\text {n.s }}$ \\
Error & 12 & 0.032 & 0.002 & - \\
Total & 17 & 3.848 & - & - \\
\hline
\end{tabular}

${ }^{* *}$ Significant at $1 \%$ probability level, ${ }^{\mathrm{ns}}$ not significant.

Seat vibrations were depended on the engine revolution and gear ratio (1,2 and 3 heavy gears) of the studied combine. It was observed that RMS acceleration was increased proportional to the engine revolution. The results indicated that there was a significant difference in the effects of both levels of engine revolutions in all studied gear ratios (Figure 3 ). Also the effects of all studied levels of gear ratio on seat vibration were significant but as can be seen in Figure 3 the effects of engine revolutions on seat vibration were stronger than that of gear ratios. In other words, the mean values for RMS of the seat vibration which is created by different engine revolutions were higher than those created by different gear ratios.

The value of vibration RMS for the combine seat increased by increasing of engine revolution from $1800 \mathrm{rpm}$ to 2500 rpm and shifting gear from 1 to 3 . The seat vibration was increased due to increase of the number of combustion courses, piston strokes and inertial forces of the engine and also increase of forward speed and the effects of the farm surface condition. In similar studies conducted on tractors and tillers in different working conditions, Dewangan \& Tewari [21] and Salokhe et al. [22] reported the same results. Moreover, all parts of the combine harvesting system such as the cutting platform, beater and concave, straw walker and sieves can play an essential role in creating vibrations.

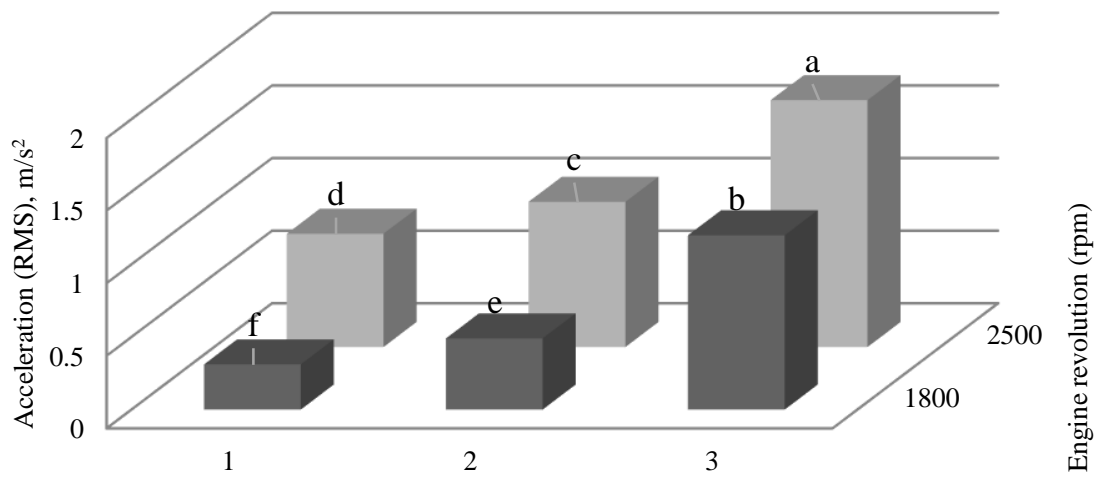

Gear ratio

Figure 3. RMS values of John Deere combine seat vibrations in the time domain at different gear ratios and engine revolution. (Nonsimilar letters indicate a significant difrence at $1 \%$ probablity level).

\section{The 1/3 Octave Band Analysis}

To make better comparison, vibration signals were investigated in the $1 / 3$ octave band and frequency domain. To calculate the $1 / 3$ octave band, the signals in the time domain were converted to the frequency domain using FFT method and then the RMS acceleration was recorded in certain frequency according to ISO 2631 standard [19].

The comparative results of vibration of the combine seat in $\mathrm{Z}$ direction based on the $1 / 3$ octave band at the different gear ratios and engine revolution of $1800 \mathrm{rpm}$ have been shown in Figure 4 . The value of vibration increased in all frequencies by increase of the gear ratio from 1 to 3. Changes rate in vibration at the engine revolution of $1800 \mathrm{rpm}$ and gear ratios of 1,2 and 3 were equal to $0.12,0.18$ and $0.34 \mathrm{~m} / \mathrm{s}^{2}$, respectively. Increase of vibrations is due to increase of combine travel speed and the effects of farm surface conditions. The same results were reported by Ahmadian et al. [13] and Taghizade-Alisaraei et al. [20]. There was not much difference in vibration values at gears 1 and 2, except in the frequencies 16 and $50 \mathrm{~Hz}$ while this difference is more perceptible at gear 3 compared to other gear ratios. Up to frequency of $12.5 \mathrm{~Hz}$, vibrations for all gears were almost identical, but vibration value increased in $16 \mathrm{~Hz}$ at gears 1 and 2 and in $20 \mathrm{~Hz}$ at gear 3 (vibration peak). Vibration values in the frequency of $16 \mathrm{~Hz}$ at gears 1 and 2 were equal to 0.3 and 0.5 
$\mathrm{m} / \mathrm{s}^{2}$, respectively and in frequency of $20 \mathrm{~Hz}$ for gear 3 reached to $1 \mathrm{~m} / \mathrm{s}^{2}$. Vibration value reached its maximum in gear 3 due to travel speed [13]. The trend of vibration acceleration value approximately was the same in higher frequencies for all studied gear ratios. The 1/3 octave band showed that differences between the vibration magnitudes in frequencies higher than $80 \mathrm{~Hz}$ were not significant for all operating conditions. This result is confirmed that the human body is more sensitive to the frequency range of $1-80 \mathrm{~Hz}$.

The effect of gear ratios on $1 / 3$ octave band of the seat vibration in $\mathrm{Z}$ direction at the engine revolution of $2500 \mathrm{rpm}$ was presented in Figure 5. There can be seen that similar to the Figure 4, vibration value increased by shifting gear from 1 to 3 in all frequencies. The vibration in $16 \mathrm{~Hz}$ at gears 1 and 2 were equal to 0.42 and $0.8 \mathrm{~m} / \mathrm{s}^{2}$, respectively and in frequency of $20 \mathrm{~Hz}$ at gear 3 was equal to $1.4 \mathrm{~m} / \mathrm{s}^{2}$. Vibration acceleration reaches its maximum for gear 3 and this can be due to increase in travel speed. Also, the combine has moving parts such as an engine, power transmission system, cutting platform, sieve, etc. that can produce such vibrations. At higher frequencies, the vibration acceleration decreased slowly. The averages of vibration acceleration at gears 1,2 and 3 at the engine revolution of $2500 \mathrm{rpm}$ were equal to 0.19 , 0.29 and $0.5 \mathrm{~m} / \mathrm{s}^{2}$, respectively. These excitations could be caused by changing in travel speed and the effects of the soil surface. These results are consistent with the results obtained by Ahmadian et al. [13]; Ahmadian et al. [25]; Servadio et al. [6]; Servadio and Belfiore, [26] and Deboli et al. [27].

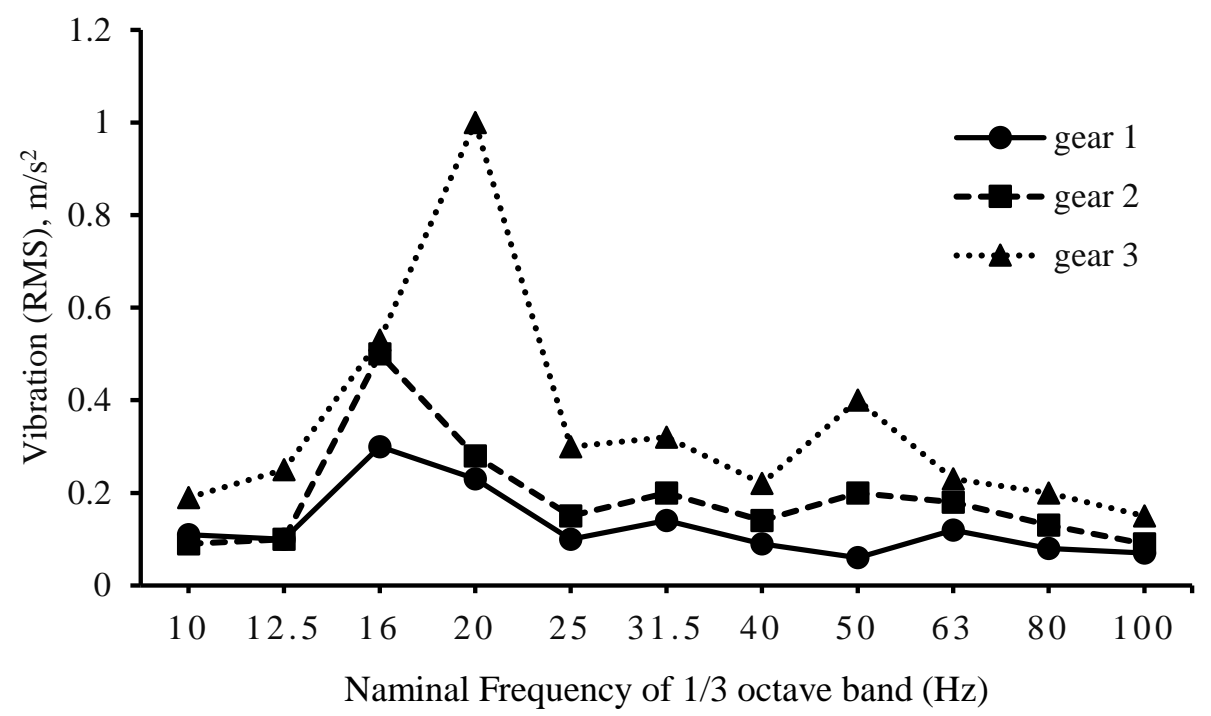

Figure 4. The 1/3 octave spectrum of seat vibration at different gear ratios and engine revolution of $1800 \mathrm{rpm}$.

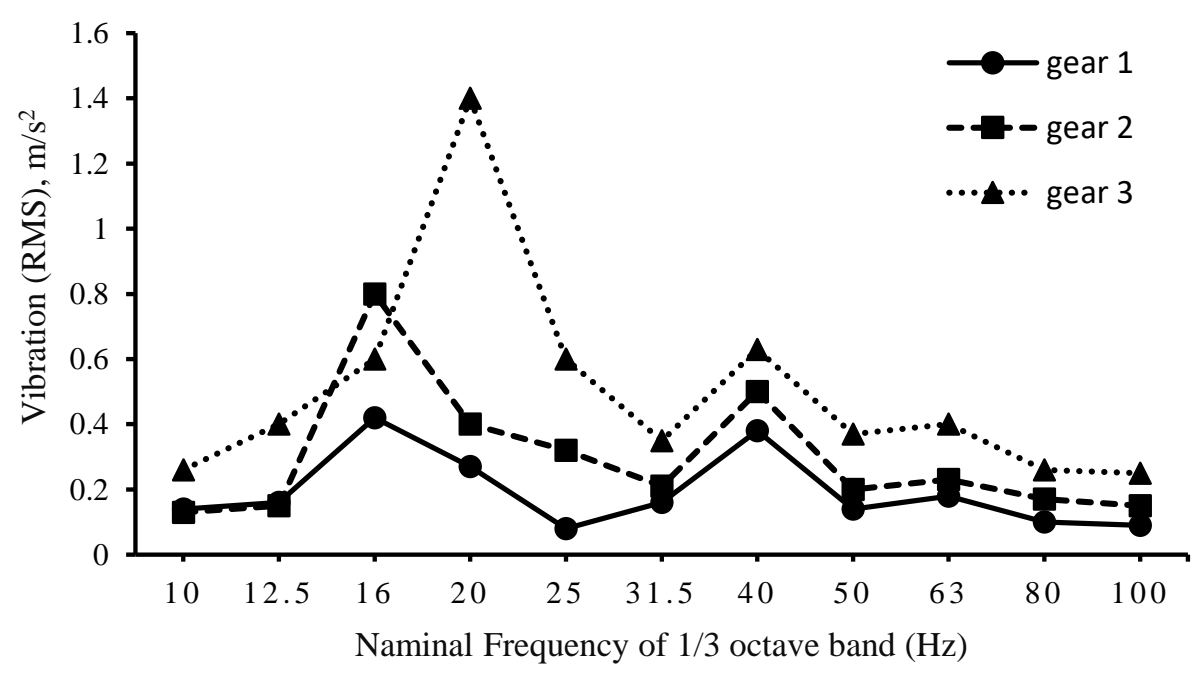

Figure 5. The 1/3 octave spectrum of seat vibration at different gear ratios and engine revolution of $2500 \mathrm{rpm}$.

The effect of engine revolution on the $1 / 3$ octave band of the combine seat vibration at different gear ratios and in $\mathrm{Z}$ direction has been shown in Figure 6. There was found that the seat vibration had variations between different engine revolutions (1800-2500 rpm) which might be due to the increase in the number of power strokes in combustion courses and piston beats per unit time [21]. In similar studies conducted in different working conditions on the tractor and tillers similar results have been reported [22. 23]. 
By increasing the gear ratio, the vibration absorption by seats reduced proportionally and rate of vibration in the combine's framework that is absorbed by its seat increased according to increase of engine revolution. In a similar study, Mehta et al. [23] reported that the origin of high-frequency vibrations is the engine and stated that these frequencies would be reduced through the seat's foam and cause less harms to the human organs.

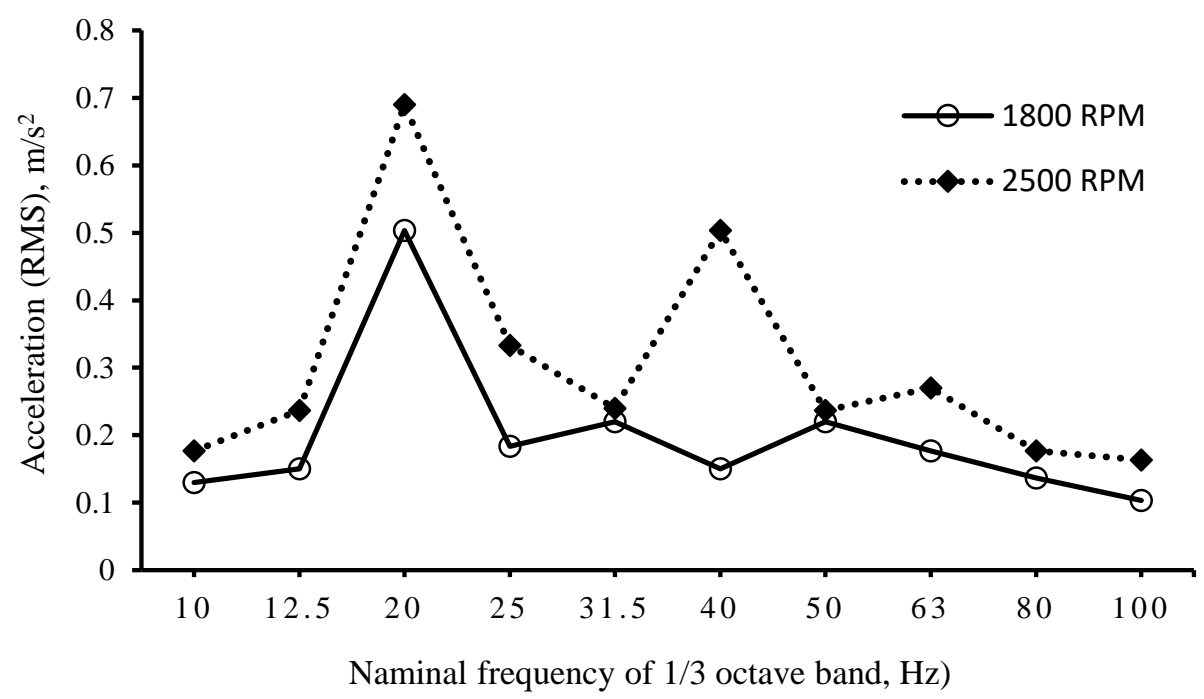

Figure 6. The 1/3 octave band of seat vibration at different engine revolutions.

\section{Allowable Exposure Time}

The exposure time for the studied combine driver at different gear ratios and engine revolution in the frequency range of 1 to $80 \mathrm{~Hz}$ has been illustrated in Figure 7 and Figure 8. According to the figures, averages of vibration were increased by increasing gear ratio and engine revolution. Therefore allowable exposure time reduced when shifting gear from 1-3 and changing engine revolution from 1800 to $2500 \mathrm{rpm}$. The user can drive for $8 \mathrm{~h}$ per day in gear 1 and 2 at engine revolution of $1800 \mathrm{rpm}$ while user is allowed to work on the John Deere combine harvester for $4 \mathrm{~h}$ using gear 3 . The allowable exposure time at the engine revolution of $2500 \mathrm{rpm}$ at gear 1 is $8 \mathrm{~h}$ per day without any problem. Using the gear 2 and 3, the combine driver is permitted to drive for $4 \mathrm{~h}$ and $2.5 \mathrm{~h}$ per day. Based on these results, it can be noted that the effect of reducing engine revolution to increase the allowable exposure time is more than that of shifting gear [24].

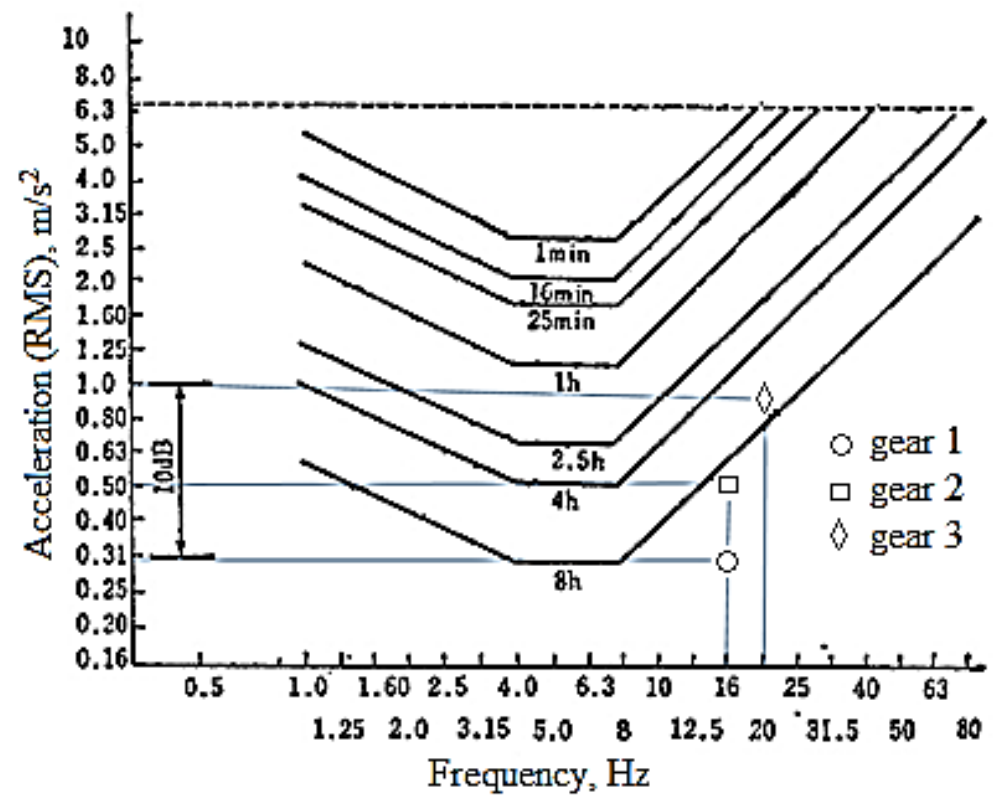

Figure 7. Exposure time for different gear ratios and engine revolution of $1800 \mathrm{rpm}$. 


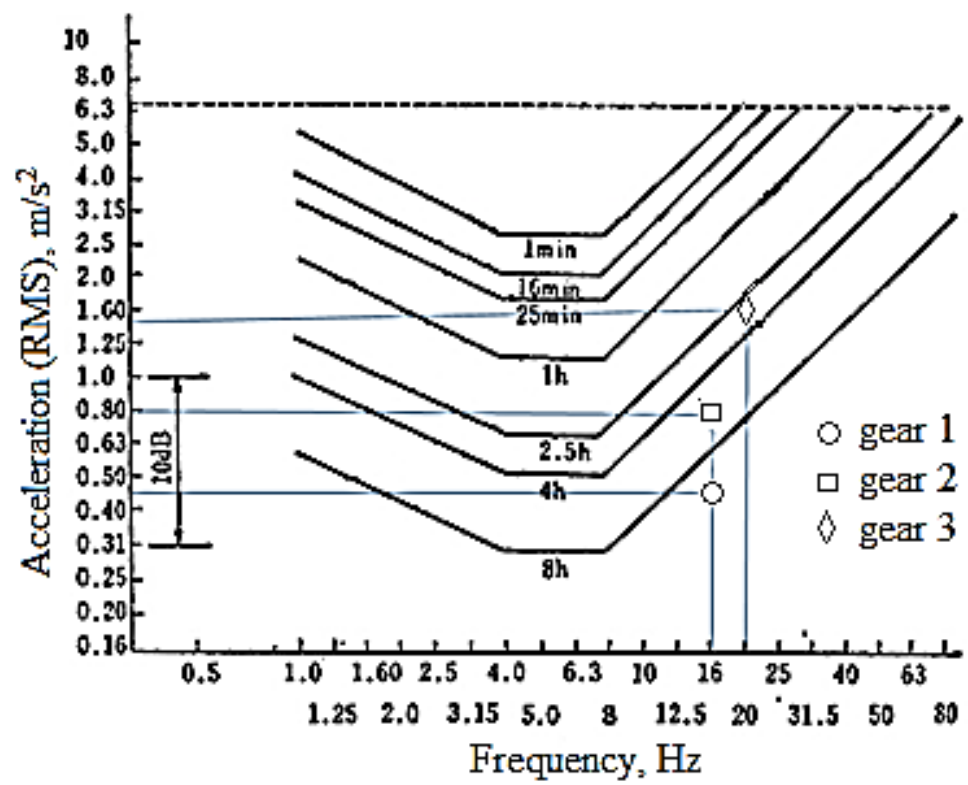

Figure 8. Exposure time at different gear ratios and engine revolution of $2500 \mathrm{rpm}$.

\section{CONCLUSIONS}

With detailed analysis of the vibration, there was observed that the effect of two essential variables, namely engine revolution and gear ratio on the vibration transmitted from the driver seat of John Deere Combine Harvester is significant at $1 \%$ probability level. Increasing of engine revolution from 1800 to $2500 \mathrm{rpm}$ and shifting gear from 1-3, would lead to increase the average RMS value of vibrations. The effect of changing engine revolution on reducing combine seat vibration was higher than that of shifting gear. Therefore, it is suggested that the user use lower engine revolution (revolution $1800 \mathrm{rpm}$ ) when using the combine. According to the Iranian standard stated by the Technical Regulations and Health Protection Committee, which sets the limit of 8 hours daily and 40 hours weekly work and based on the findings of this study, the drivers can drive John Deere Combine Harvester at the engine revolution of $1800 \mathrm{rpm}$ using gear 1 and 2 and the engine revolution of $2500 \mathrm{rpm}$ using gear 1 for $8 \mathrm{~h}$ per day without any problem.

\section{REFERENCES}

[1] Jaikumar S, Bhatti SK, Srinivas V. Emission and vibration characteristics of Niger seed oil biodiesel fueled diesel engine. Journal of Mechanical Engineering and Sciences. 2019; 13: 5862-5874.

[2] Jahanbakhshi A, Ghamari B, Heidarbeigi K. Effect of engine rotation speed and gear ratio on the acoustic emission of John Deere 1055I combine harvester. Agricultural Engineering International: CIGR Journal. 2016; 18: 106-112.

[3] Jahanbakhshi A, Ghamari B, Heidarbeigi K. Assessing acoustic emission in 1055I John Deere combine harvester using statistical and artificial intelligence methods. International Journal of Vehicle Noise and Vibration. 2017; 13: 105-117.

[4] Jahanbakhshi A, Heidarbeigi K. Analysis and prediction of noise pollution of garden tractor using statistical methods, artificial intelligence and ANFIS. Iranian Journal of Biosystems Engineerin. 2019; 50: 499-512. (In Press).

[5] Isham MF, Leong MS, Hee LM, Ahmad ZAB. Iterative variational mode decomposition and extreme learning machine for gearbox diagnosis based on vibration signals. Journal of Mechanical Engineering and Sciences. 2019; 13: 4477-4492.

[6] Servadio P, Marsili A, Belfiore NP. Analysis of driving seat vibrations in high forward speed tractors. Biosystems Engineering. 2007; 97: 171-180.

[7] Magnusson ML, Pope MH, Wilder DG, Areskoug B. Are occupational drivers at increased risk for developing musculoskeletal disorders. Spine. 1996; 21: 710-7.

[8] Griffin M J. Handbook of human vibration. 2012; Academic press.

[9] El Sayed M, Habashy S, El Adawy M. Evaluation of whole-body vibration exposure to Cairo subway (Metro) passengers. International Journal of Computer Applications. 2012; 55: 7-18.

[10] De Temmerman J, Deprez K, Anthonis J, Ramon H. Conceptual cab suspension system for a self-propelled agricultural machine, Part 1: Development of a linear mathematical model. Biosystems Engineering. 2004; 89: 409-416.

[11] Marsili A, Ragni L, Santoro G, Servadio P, Vassalini G. PM-Power and machinery: innovative systems to reduce vibrations on agricultural tractors: Comparative analysis of acceleration transmitted through the driving seat. Biosystems Engineering. 2002; 81: 35-47.

[12] Hostens I, Ramon H. Descriptive analysis of combine cabin vibrations and their effect on the human body. Journal of Sound and Vibration. 2003; 266: 453-464.

[13] Ahmadian H, Hassan-Beygi S R, Ghobadian B. Investigating a power tiller handle and seat vibration on transportation mode. Agricultural Engineering International: CIGR Journal. 2014; 16: 194-206. 
[14] Pel JJM, Bagheri J, Van Dam LM, Van Den Berg-Emons HJG, Horemans HLD, Stam HJ, Van der Steen J. Platform accelerations of three different whole-body vibration devices and the transmission of vertical vibrations to the lower limbs. Medical Engineering and Physics. 2009; 31: 937-944.

[15] Agriculture Statistics 2013; Ministry of Agriculture publication. Vol: 2, 16 pages. (In Persian).

[16] Tewari VK, Prasad N. Three-DOF modelling of tractor seat-operator system. Journal of Terramechanics. 1999; 36: $207-219$.

[17] Taghizadeh-Alisaraei A, Tavakoli-Hashjin T, Ghobadian B. An investigation of seat vibration in Universal 650M tractor. Iranian Journal of Agricultural Science. 2007; 38: 571-580. (In Persian).

[18] Iranian National Standard No. 14133. Wheeled agricultural tractors and field machinery-Measurement of whole-body vibration users. $1^{\text {st }}$ Edition. (In Persian).

[19] International Organization for Standardization, ISO 2631-1. Mechanical vibration and shock-evaluation of human exposure to whole-body vibration-Part 1: General requirements. The Organization. 1997.

[20] Taghizadeh-Alisaraei A, Ghobadian B, Tavakoli-Hashjin T, Mohtasebi SS. Vibration analysis of a diesel engine using biodiesel and petrodiesel fuel blends. Fuel. 2012; 102: 414-422.

[21] Dewangan KN, Tewari VK. Characteristics of hand-transmitted vibration of a hand tractor used in three operational modes. International Journal of Industrial Ergonomics. 2009; 39: 239-245.

[22] Salokhe VM, Majumder B, Islam MS. Vibration characteristics of a power tiller. Journal of Terramechanics. 1995; 32: 181197.

[23] Mehta CR, Shyam M, Singh P, Verma RN. Ride vibration on tractor-implement system. Applied Ergonomics. 2000; 31: 323328 .

[24] Sam B, Kathirvel K. Vibration characteristics of walking and riding type power tillers. Biosystems Engineering. 2006; 95: 517528.

[25] Ahmadian H. Hassan-Beygi SR. Ghobadian B. Power tiller vibration acceleration envelope curves on transportation mode. Journal of Vibroengineering. 2013; 15: 1431-1441.

[26] Servadio P, Belfiore NP. Influence of tyres characteristics and travelling speed on ride vibrations of a modern medium powered tractor Part I: Analysis of the driving seat vibration. Agricultural Engineering International: CIGR Journal, 2013; 15: 119-131.

[27] Deboli R, Calvo A, Preti C. Whole-body vibration: Measurement of horizontal and vertical transmissibility of an agricultural tractor seat. International Journal of Industrial Ergonomics. 2017; 58: 69-78. 